\title{
Research on the Integration of Highway Ports and Intermodal Transportation in Jiangxi Province
}

\author{
Lin Feng \\ Jiangxi Institute of Economic Administrators, Jiangxi Nanchang 330088, China \\ linfengjx@126.com
}

Keywords: Highway port; Intermodal node; Single window; Intermodal agreement

\begin{abstract}
Through the analysis of the dual indicators of social logistics cost and overall service lev el in Jiangxi Province, and clarifying the situation of continuous pursuit of industrial demand and pa ssive development in the past 30 years, the lack of global logistics design and long-term planning is the root cause of the industry's development lag. Comparative data with surrounding provinces at th e same time, learning from the international peers' advanced service concept, unified planning awar eness and the experience of integrated infrastructure construction, the development of highway port and intermodal integrated construction supported by a single window of logistics information servic e platform was explored. By using high-grade waterway and railway resources, the water, iron and highway intermodal transportation at the first-level node of the highway port taken as the leading fa ctor, and the development strategy of the intermodal transportation is assisted by the rail transit of $\mathrm{t}$ he secondary node of the highway port.
\end{abstract}

\section{Introduction}

After 30 years of sustained rapid economic growth, China has become the world's first trading country and the second largest economy, at the same time, China's logistics industry has not made the achievement of synchronizing with the economic development, which is worthy of further study in logistics circles. And to discuss the backward situation of Jiangxi logistics, whose level of development is lower than the national average, may help us to find the representative reasons why the logistics industry has lagged behind the economic development in the past 30 years. To find a feasible strategy to improve the backward situation of Jiangxi logistics.

\section{Facing up to the backward situation of logistics cost and service level in Jiangxi}

The ratio of the total cost of social logistics to the corresponding GDP in a region can reflect the level of the single index of the total cost of social logistics in the region. In order to evaluate the development level of logistics in a region, another important index-logistics service level considered at the same time. Whether the level of logistics service level is the same and the social logistics cost is high, or the social logistics cost is similar but the level of logistics service is low, all directly explain the defects of the factors that determine the logistics cost or service level. If the social logistics costs are high and the level of logistics services is still low, then the factors determining the two key indicators may be insufficient at the same time. Even deeper factors are missing.

(1) The ratio of the total cost of social logistics to GDP in Jiangxi Province continues to be higher than the national average.

From the comparison of the ratio of total social logistics cost to GDP in Jiangxi Province and China from 2011-2017, we can see (see table 1) that the index parameter representing the level of social logistics cost in Jiangxi Province has been consistently higher than the national average for many years. Taking 2013 as an example, the total cost of social logistics in our country is 10.2 trillion yuan, accounting for $18.0 \%$ of GDP, and 19.1\% in Jiangxi Province in the same year. In developed countries with a higher level of logistics services than in China, the United States 
accounted for 8.5 percent, while in BRICS countries with similar levels of economic development and logistics services, India accounted for 13 percent and Brazil for one. 1.6. Compared with the domestic and foreign countries, the cost of social logistics in Jiangxi Province is on the high side, and compared with the developed countries, Jiangxi Province is in a backward position to determine the level of logistics development.

Table 1 Ratio of total social logistics costs to corresponding GDP in China and Jiangxi, 2011-2017

\begin{tabular}{|c|c|c|}
\hline year area & China & Jiang xi \\
\hline 2011 & $17.8 \%$ & $19.2 \%$ \\
\hline 2012 & $18.0 \%$ & $19.2 \%$ \\
\hline 2013 & $18.0 \%$ & $19.1 \%$ \\
\hline 2014 & $16.6 \%$ & $17.6 \%$ \\
\hline 2015 & $16.0 \%$ & $17.4 \%$ \\
\hline 2016 & $14.9 \%$ & $16.9 \%$ \\
\hline 2017 & $14.6 \%$ & $16.6 \%$ \\
\hline
\end{tabular}

(2) The supply of logistics resources is scattered and the overall service level needs to be improved.

1) Each logistics park has a small scale of logistics companies on their own to divide the highway trunk, branch market, and other logistics companies dominated by the market. In the past ten years, the logistics of Jiangxi Province dominated by road transportation, which accounts for an average of $90 \%$ of the province's freight volume (see figure 1). The logistics companies engaged in highway transportation mainly originated from the "information department" in the early period. Depending on their own advantages of transportation network resources and vehicle and cargo resources in their own development history, they split the share of survival in the free competition market. Scattered in the entire Jiangxi Province road for transport market.

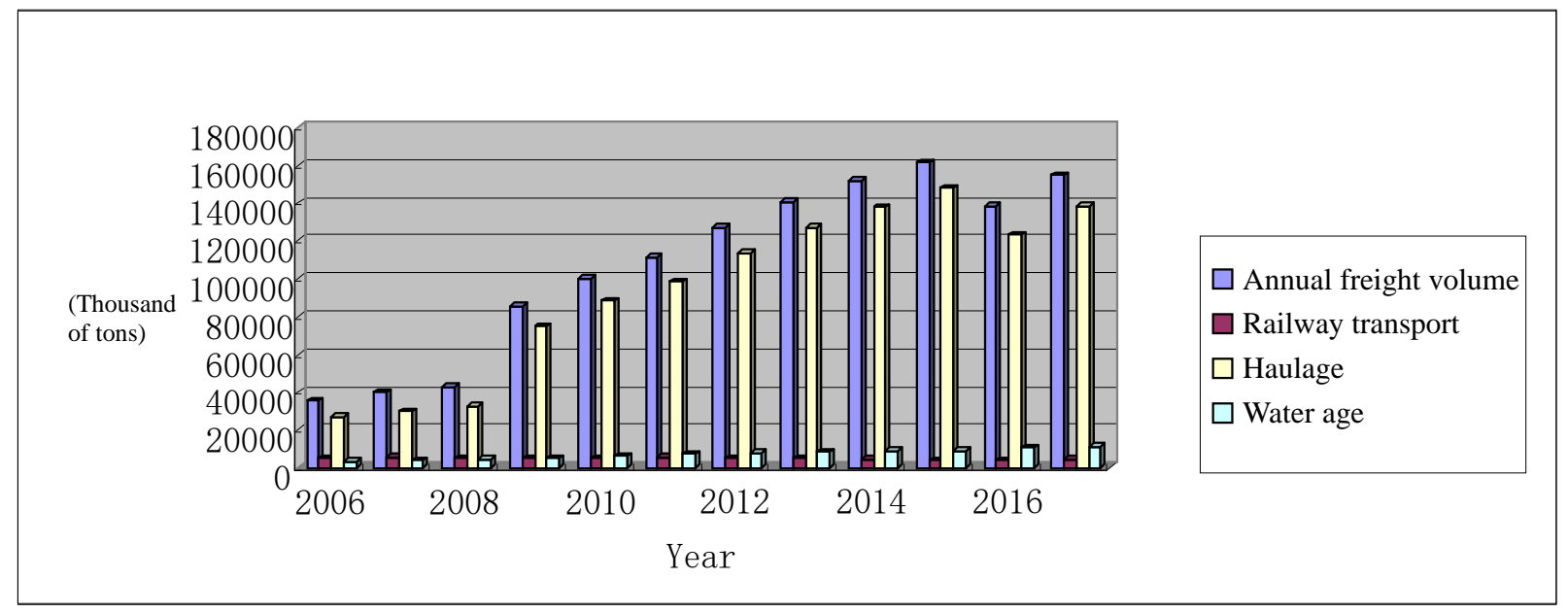

Fig. 1 Column list of freight volume in Jiangxi province 2006-2017

2) Each highway of information of service platform divided into one side, so it is difficult to give full play to the overall utility of unified resource allocation. The competing highway information of service platform, represented by Wanji logistics and transmissible logistics, can allocate market resources through information technology in some areas, that is, within the scope of logistics market resources owned by its own platform. However, it cannot achieve the overall utility of the unified allocation of logistics resources in the province market. The operator of the information service platform needs a sustained high investment to maintain the network platform independently, and the market share of the information service platform must reach a certain scale in order to make the operator survive. And seek further development. Because of the competition between the platforms and the market situation in which they seek to stand on their feet, the information service platform fails to play its due role in the effective allocation of logistics market resources. 
3) Water, iron transport coverage is small, showing a state of affairs. As be seen from Table 1, the volume of water transportation and railway transportation in Jiangxi Province accounts for a very small share of the province's freight volume. In 2017, Jiangxi's water and iron transport volume totaled 162.79 million tons, accounting for only 10.55 tons of the province's total transportation volume (1.54353 billion tons). The waterway and railway transport departments both belong to the central enterprises. Although both have the will to integrate with the logistics construction in Jiangxi Province, they have also made certain steps in the practice of production activities, but, Each has significant independence in global planning and operational practices (for comparison of water and rail traffic, see chart)2)

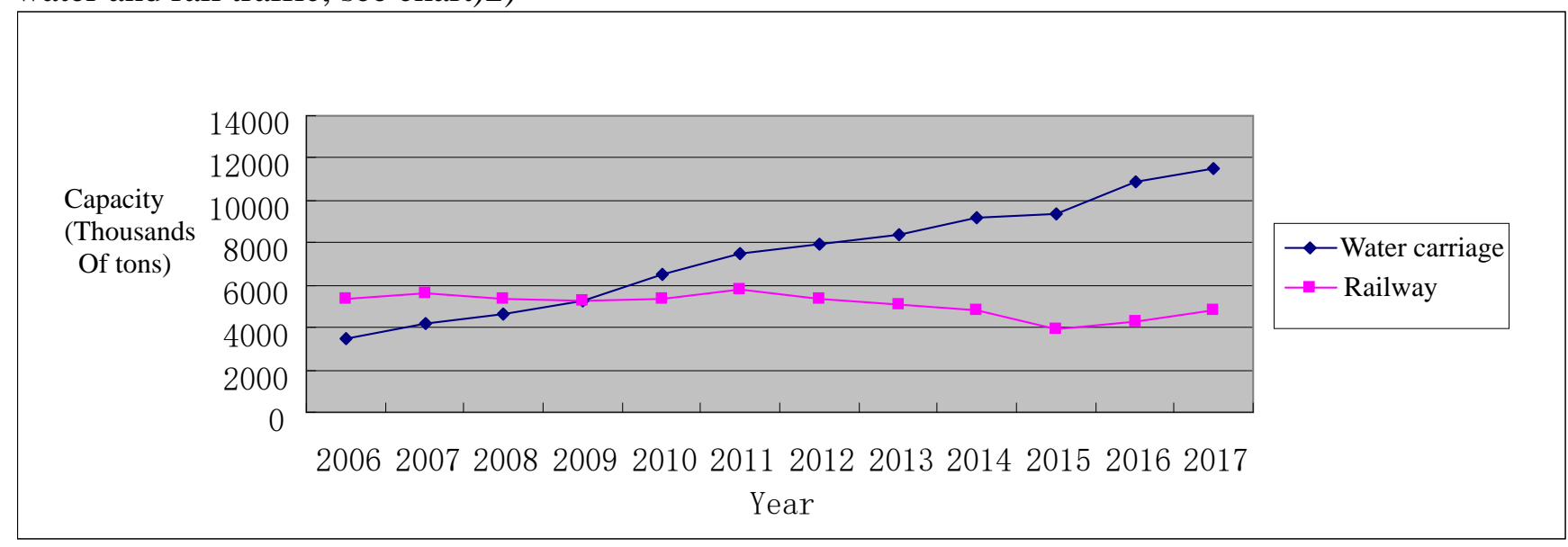

Figure 2 Trends of Jiangxi water and rail freight volumes 2006-2017

4) Air logistics cargo volume is small, complete system. According to the State Administration of Civil Aviation's ranking of Air Airport Throughput of 2017, Jiangxi Province's air cargo and postal throughput was 63607.4 tons in that year, and Chang bei Airport was 52262.4 tons. None of them reached 1/10000 of the total cargo transportation volume of the province ("Statistical Bulletin on the National Economic and Social Development of Jiangxi Province 2017"). At present, Jiangxi Province's aviation logistics system is completely self-contained. Airfreight forwarders in the market mainly carry out the connection with other modes of transport.

\section{Deep analysis of the causes}

\subsection{Discussion on the reasons for the lag of Logistics Development in academic circles}

Since the reform and opening up, with the continuous development of China's economy, the academic discussion on the reasons for the backward development of logistics has never stopped. Among them, the representative views are mainly lack of logistics planning, serious repetitive construction, high idle rate of equipment, low logistics efficiency, unreasonable logistics costs, and so on. There related to logistics concepts, management bodies. In summary, the academic discussion on this topic is indeed justified, indeed, from the current situation of the logistics industry, analyzed the direct causes under various phenomena. Need to dig further, must be highly valued by academic circles.

\subsection{Many reasons brought up by the fact that the logistics industry has passively developed for a long time in the past 30 years.}

In the past 30 years, the "industry transfer" of the logistics industry has been the root cause of the phenomenal factors, such as the chaos of the logistics structure in Jiangxi Province and even the whole country, the serious duplication of construction, the high idle rate of equipment, the low efficiency and the high logistics cost. The situation of demand and passive development, the lack of the overall logistics design and long-term planning necessary for the economic and social development to a certain stage, has led to the above-mentioned various "phenomenal factors" that cause the high cost of comprehensive social logistics. In addition, the difficulty of improving and 
improving the level of logistics services, which are difficult at the primary stage of economic development. With the sustained and rapid development of economy today, China's economic construction has begun to enter a new stage of transformation and upgrading, raising quality and increasing efficiency, but also the key period in which the supply side of logistics in Jiangxi Province be changed.

\section{Compared with the surrounding provinces, Jiangxi has the space and resources to take advantage of the cost of water transportation.}

By comparing the ratio of total social logistics cost to GDP in Hubei, Hunan, and Anhui and Jiangxi provinces. and the structure of freight volume in each province (the percentage of different modes of transportation to the total freight volume), it is not difficult to find out that the ratio of the total cost of social logistics to GDP in the four provinces of Hubei, Hunan, Anhui and Jiangxi is not difficult to find. The total cost of social logistics in Jiangxi Province is as high as $16.9 \%$, which is higher than that in the three neighboring provinces. At the same time, we can see that the three provinces of Hubei, Hunan and Anhui are all larger than Jiangxi Province in terms of the volume of waterway transportation with the best transport cost. In the transport cost of the highest volume of road transport, the surrounding three provinces are smaller than Jiangxi Province.

Table 2 Total social logistics costs and freight structure in Hubei, Hunan, Anhui and Jiangxi provinces in 2016

\begin{tabular}{|c|c|l|l|lr|}
\hline province & $\begin{array}{l}\text { Waterway } \\
\text { transport } \\
\text { capacity }\end{array}$ & $\begin{array}{l}\text { Highway } \\
\text { traffic } \\
\text { volume }\end{array}$ & $\begin{array}{l}\text { Railway } \\
\text { transport } \\
\text { volume }\end{array}$ & $\begin{array}{l}\text { Total } \\
\text { Logistics } \\
\text { ratio GDP }\end{array}$ & $\begin{array}{r}\text { Social } \\
\text { Duty }\end{array}$ \\
\hline Hubei & $22 \%$ & $75 \%$ & $3 \%$ & $15.4 \%$ \\
\hline Hunan & $11 \%$ & $87 \%$ & $2 \%$ & $16.0 \%$ \\
\hline Anhui & $30 \%$ & $67 \&$ & $3 \&$ & $16.5 \%$ \\
\hline Jiangxi & $8 \%$ & $89 \&$ & $3 \&$ & $16.9 \%$ \\
\hline
\end{tabular}

As we all know, among all the transportation modes, waterway transportation has the most cost advantage, and the full utilization of waterway transportation resources will inevitably bring about significant effect in reducing the total cost of social logistics. First, Jiangxi, Hubei, Hunan and Anhui provinces are located in the middle part of the Yangtze River. They belong to the provinces in the middle and lower reaches of the Yangtze River. They share the natural Yangtze River waterway resources and each sits at the important ports along the Yangtze River. The Yangtze River has the advantages of shipping resources; secondly, Jiangxi has three sides surrounded by mountains, the mouth is open to the north, the river network distributed in the province. In addition, the five major water systems, Poyang Lake, merge into the Yangtze River, which is extremely rich in water resources; the Ganjiang River runs from north to south, covering 751 kilometers in length, with a large amount of water. It is the second largest tributary of the Yangtze River, with Guixi and Yingtan in the east of the Yangtze River, and together with the Ganjiang River, it has been included in the waterway grade-upgrading plan of Jiangxi Province in the 13th Five-Year Plan. It estimated that by 2020, the whole line of the Ganjiang high-grade waterway will reach the standard, and the Xinjiang high-grade waterway will meet the standard. Therefore, Jiangxi Province has both space and resources under the present economy and natural conditions to improve the structure of freight transport and make full use of waterborne transportation. This advantage and reduce the total cost of social logistics.

\section{Foreign experience}

5.1 FedEx's concept of leading service and global planning inherited and developed by the global logistics industry.

FedEx founder Frederick W. Smith's "express center distribution theory" contains the concept of 
advanced service and global planning, which has brought an unprecedented revolution to the global logistics industry, and has learned, used for reference and developed by the world logistics giants. In the 1970s, Frederick W. Smith was very sensitive to foresee the huge potential demand for express delivery services in the U.S. market, which was in the midst of a special period of computer technology development. With an extremely advanced sense of service and economic mind, the "express center distribution theory" founded, and put into practice in the United States. To achieve the United States Within the scope of the "overnight delivery" service, within three short years, it has become the absolute dependence of the major industry merchants in the United States computer industry, not only in terms of the time limit for logistics and transportation, but also in bringing the American industry into a brand new temple, with its high quality. Low-cost door-to-door services and scale operations make the global industry refreshing, so far for the global industry heritage and development.

\subsection{The unified national planning of the German logistics park has emulated by many European and American countries.}

The research results of logistics planning in Germany closely related to the social practice. The academic logistics elite is active in the national logistics planning, and the latest research results are directly used in the national logistics planning and construction. In the 1980s, the German government divided the country into six major logistics regions (up to now, 35 parks), and made it clear that two or more modes of transport could converge as one of the conditions for the selection of regional logistics centers. The government participates in the completion of the logistics and intermodal infrastructure of the centers, signs a cooperation agreement with the logistics enterprise committee responsible for the day-to-day operation of the park on a non-profit basis, and clarifies the responsibilities and rights of both the government and the enterprise. Benefits and obligations, constrains the park operation must conform to the national logistics strategy request, has provided a standardized and orderly logistics transportation service system for the whole Germany. This long-term measure is the fundamental reason why the social logistics cost of Germany accounts for the GDP 10\%, and becomes the object that developed countries in Europe and America have emulated one after another.

\subsection{The overall planning of the United States' intermodal transport infrastructure is a solid foundation for the United States' modern logistics system}

The development of American logistics attributed to the research results of integrated transportation network and multi-link transportation system, which applied to the logistics planning and infrastructure in the United States. First, a dense and accessible comprehensive transportation network covering most parts of the United States, especially inland, provides the basis for the development of the United States logistics industry; secondly, the greatest benefit to the American logistics industry of the application of the combined transport system is the reduction of integrated transport costs. Since 1890, the actual cost of U.S. rail transport per tone has fallen from 20 cents to 2 cents, thanks to the continuous improvement of the combined transport infrastructure and multi-link operating system. Combined Look, the average level of US railway freight is the lowest in the world, there are few tolls for road transportation, and the cost of land use in logistics parks is relatively low. All these achievements are due to reasonable planning and infrastructure construction of the combined transport system.

\section{The Breakthrough of getting rid of the backward situation of Logistics}

(1) Construction of a unified logistics information service platform single window to realize the symmetry of information between supply and demand in the whole market

By the unified planning of the government, the logistics information of service companies in operation reach a single window cooperation agreement, build a unified public platform of logistics information service in the whole province, and realize the complete symmetry of the information between the supply and demand sides in the logistics market. First, all the previously registered 
supply and demand users of the logistics information service companies in operation can fully share the supply and demand information of other companies in the new single window; second, the new, The old registered users can only share all the information and enter into transactions in the single window platform. Third, the information service companies in the camp have reached equity cooperation and profit-sharing agreement to operate the single window platform. Single window the port public platform can realize the complete sharing of the information between supply and demand, improve the information symmetry of the whole logistics market, allocate the resource elements of the logistics market efficiently in the overall scope, and reduce the transaction cost of the whole logistics market.

(2) Based on the single window of logistics information service platform, the integrated construction of highway port and intermodal transport is completed.

Supported by a single window of the unified logistics information of service platform of the whole province, relying on the waterway resources of "two horizontal and one vertical" and the railway planning of "80\% and $80 \%$ ", the construction of highway port and intermodal transport integration in Jiangxi Province has been completed. Open up a new phase of logistics. The highly unified highway port with high information efficiency combs the logistics market of business chain and optimizes the allocation of resources between supply and demand. It can clearly see from the comparison of the market business chain before and after the construction of single window highway port (Fig. 3 and 4). Before the construction of highway port supported by single window of logistics information of service platform, only the business chain between logistics supplier and demand side has been abnormal. Given the complexity and complexity of the logistics market, it is even more difficult to imagine the intensity of the chain. After the operation of the highway port, all the parties involved in the logistics industry have a business chain relationship with the highway port, presenting a center with the distribution and clarity of the eight parties. An orderly situation the structure of the business chain is undoubtedly simple and efficient, creating extremely favorable conditions for the development of integrated road, rail and waterway transport.

(3) Promote the specialized development of logistics supply side and improve the overall service level of logistics industry

The operation of single window of logistics information of service platform will promote the development of logistics supplier towards specialization. The information resources of the logistics suppliers are public, and the different service advantages of the suppliers highlighted in the market competition of survival of the fittest, which is constrained by different operating scale conditions and the pressure of the survival and development of the enterprises. Supply parties must choose to play their own service advantages as far as possible and go to the road of professional development in order to seek a place in the supply chain of logistics. The specialized development of logistics suppliers, the further maturity of logistics outsourcing market, the formation of logistics supply chain, and the overall improvement of logistics services in Jiangxi Province Level.

\section{Suggestions on Integrated Construction Strategy of Highway Port and Intermodal Transport in Jiangxi Province}

(1) The city of railway freight marshalling station flowing along the high grade waterway sets up a single window of logistics information service platform as the supporting highway port and the primary node of the intermodal transport to construct the main vein of water, iron and road combined transport

In accordance with the "13th Five-Year Plan for the Development of Comprehensive Traffic and Transportation system of Jiangxi Province" in the spirit of construction of waterway, railway and highway projects, the railway freight marshalling station, which flows along "two horizontal and one vertical" high grade waterways. Setting up the highway port and intermodal primary node supported by the single window of the unified logistics information of service platform in Jiangxi Province to construct the main vein of water, iron and road intermodal transport in Jiangxi Province. The construction of intermodal transport is the only way to improve logistics service quality. In order to improve the present situation of logistics in Jiangxi Province, it is necessary to carry out the 
basic and software construction of container transport.

Transport infrastructure to achieve seamless links. The "seamless link" is used as the standard for the intermodal infrastructure construction of the first class node, that is, the freight train track construction enters the port container loading and unloading operation area, and under the condition of water and iron transport. the realization of container unloading is the loading of the freight train at the same time; Under the condition of the combined transport of iron and water. The realization of the freight train unloading is the loading of the container at the same time, to reduce the loading and unloading times of the container in the intermodal link and reduce the loading and unloading cost.

The information sharing of ship stowage and freight train formation is the most important part in the construction of intermodal transport software. The key to realize the real seamless intermodal link lies in the construction of the intermodal transport software, which requires the cooperation of the railway carrier and the shipping operator in their respective fields of information system. First of all, under the condition of water and rail transport, the railway carrier must obtain the information of the ship's cargo manifest coming from the shipping operator, which is about to arrive at the port, before approving the freight train marshalling plan. All intermodal containers should be included in the railway truck-marshalling plan. Secondly, under the condition of hot metal intermodal transport, the agent of the shipping operator must have access to the space before the booking deadline. From the rail carrier, the same shipping time of the container information, form a loading list after the preparation of stowage plan.

(2) Setting up secondary nodes of highway ports and combined transport along the prefecture-level cities passing along the railway to form a road and railway intermodal network covering the whole province

The secondary nodes of highway port and intermodal transport supported by single window of logistics information of service platform should be set up in cities with railway container yard operating conditions, and the ability of allocating market resources by single window can utilized. We will cover the entire territory of Jiangxi Province by road and rail transport services. In this way, the operation of one or two nodes of highway ports and intermodal transport in Jiangxi Province can not only take into account the import and transit of bulk raw materials needed for heavy industry production in the province. But also dredge the intermodal channels for the entry and exit of bulk grains into and out of Jiangxi Province. At the same time, it also lays the foundation for the national intermodal transport channel between the south and north of Jiangxi.

(3) Completion of the preparation of intermodal transport agreements and harmonization of intermodal transport documents to create preconditions for the conduct of actual combined transport

It needs a process from occurrence to maturity to carry out the actual intermodal transport business in an all-round way. It is a feasible choice to start the intermodal transport business locally through the multimodal transport agreement between the two or more parties and the unified intermodal transport documents, which agreed by both parties. It is also the only way to carry out the intermodal transport in an all-round way. Dingshui Railway, High-speed Railway and Multimodal Transport Agreements clarify the responsibilities, obligations and rights of the parties, clarify the principles of risk division in cargo transportation, warehousing, loading and unloading, and handing over operations, as well as the legal basis for handling abnormal transport, claims, arbitration and litigation procedures; on the other hand, with international standards. The multimodal bill of lading shall approved and uniformly used by all parties under the terms of the intermodal transport agreement. The completion of the above two aspects of the basic work can create preconditions for the local development of actual transport.

Note:

(1) Two horizontal: Jiangxi section of the Yangtze River, Xinjiang; one vertical: Ganjiang.

(2) Eight open: start the Jiangxi-Shenzhen special railway; 80\%: build Changji, Gan and so on 8 railways. 


\section{Acknowledgements}

[Fund projects] General item of Science and Technology Project of Jiangxi Education Department (item No.: GJJ171396).

\section{References}

[1] Pang Biao, Logistics supply side Reform Strategy [J]. China Logistics \& Purchasing Co., Ltd (1).

[2] Wu Xing, Belt and Road, A study on the Development Strategy of Sea-Rail Transport in China [J]. Navigation 2016 (1).

[3] Wu H l, exploring the Development of International Multimodal Transport in China [J]. China Science and Technology Expo 2016 (3).

[4] H P f, Research on the Construction of Railway Logistics Center and Multimodal Transport Hub Logistics Park [J]. Land Bridge Vision 2016 (1).

[5] Wang Ming, supply-side reform will eliminate backward services [J] logistics era 2016 (1).

[6]Ding $\mathrm{J} \mathrm{f}$, accelerate the supply-side reform of China's logistics industry [J]. China Storage and Transportation 2016 (2).

[7] Gong M c, a study on Highway Port Construction of the second and third Class cities in China [J]. Cooperative economy and Science and Technology 2016 (2)

[8] Deng W, the study of setting up Urban Distribution platform based on Highway Port Mode [J]. Logistics Engineering Management 2016 (2)

[9] Wang q J, ou Ning, Yu Jun, Analysis on the Development of China's Highway Port Logistics Model [J]. "Logistics Engineering and Management." 2016 (1).

[10] Fan Z y, du J t, Lin Tan. Accelerating the Development of Multimodal Transport: business implications for the United States. [J] Comprehensive Transportation Volume 37, No. 4, 2015 (4).

[11]G Y f, big data era Highway Logistics [J] Enterprise Research 2014 (12).

Author: Lin Feng (1967.06), male, Han, Ning gang, Jiangxi, Master, Professor, mainly engaged in international logistics teaching and research. 